Collection: IUFRO 7.01.00 - COST Action FP0903, Kaunas (Lithuania - 2012)

"Biological Reactions of Forest to Climate Change and Air Pollution"

Guest Editors: Elena Paoletti, Andrzej Bytnerowicz, Algirdas Augustaitis

\section{Rapid assessment of wind storm-caused forest damage using satellite images and stand-wise forest inventory data}

\author{
Donatas Jonikavičius ${ }^{(1)}$, Gintautas Mozgeris ${ }^{(2)}$
}

This paper introduces a method for rapid forest damage assessment using satellite images and stand-wise forest inventory data. Two Landsat 5 Thematic Mapper (TM) images from June and September 2010 and data from a forest stand register developed within the frameworks of conventional stand-wise forest inventories in Lithuania were used to assess the forest damage caused by wind storms that occurred on August 8, 2010. Satellite images were geometrically and radiometrically corrected. The percentage of damage in terms of wind-fallen or broken tree volume was then predicted for each forest compartment within the zone potentially affected by the wind storm, using the non-parametric $k$-nearest neighbor technique. Satellite imagery-based difference images and general forest stand characteristics from the stand register were used as the auxiliary data sets for prediction. All auxiliary data were available from existing databases, and therefore did not involve any added data acquisition costs. Simultaneously, aerial photography of the area damaged by the wind storm was carried-out and color infrared (CIR) orthophotos with a resolution of $0.5 \times 0.5 \mathrm{~m}$ were produced. A precise manual interpretation of the effects of the wind storm was used to validate satellite image-based estimates. The total wind damaged volume in pine dominating forest $(\sim 1.180 .000$ $\left.\mathrm{m}^{3}\right)$ was underestimated by $2.2 \%$, in predominantly spruce stands $(\sim 233.000$ $\mathrm{m}^{3}$ ) by $2.6 \%$ and in predominantly deciduous stands $\left(\sim 195.000 \mathrm{~m}^{3}\right)$ by $4.2 \%$, compared to validation data. The overall accuracy of identification of winddamaged areas was around $95-98 \%$, based solely on difference data from satellite images gathered on two dates.

Keywords: Forest Damage, Satellite Images, Change Detection, k-Nearest Neighbour

\section{Introduction \\ The assessment of wind-caused forest da- mage includes some specifics that distin- guish it from other tasks of detection and measuring of forest changes, at least in the context of Lithuanian forestry conditions. Fast and accurate determination of affected areas of forest and the severity of the damage are essential to enable forest managers to}

take immediate action on sanitary felling, timber processing and reforestation. Damage is usually geographically concentrated, some areas being difficult to access and measure in the field; however, all forests in Lithuania are precisely mapped and attributed by stand-wise forest inventories (Mozgeris et al. 2008).

This paper introduces a method of asses-

$\square$ (1) Laboratory of Geomatics, Institute of Land Management and Geomatics, Aleksandras Stulginskis University, Studentu 11, LT-53361 Akademija, Kaunas distr. (Lithuania); (2) Institute of Forest Management and Wood Science, Aleksandras Stulginskis University, Studentu 11, LT-53361 Akademija, Kaunas distr. (Lithuania)

@ Donatas Jonikavičius (donatas.jonikavicius@asu.lt)

Received: Jul 31, 2012 - Accepted: Feb 26, 2013

Citation: Jonikavičius D, Mozgeris G, 2013. Rapid assessment of wind storm-caused forest damage using satellite images and stand-wise forest inventory data. iForest 6: 150-155 [online 2013-04-08] URL: http://www.sisef.it/iforest/contents/?id=ifor0715-006

Communicated by: Agostino Ferrara sing the forest damage caused by a wind storm on August 8, 2010, in Lithuania. The introduced method may also be useful for solving other remote sensing based change detection tasks. The solution is based on integrating methodological approaches originating from two areas of satellite image usage related to the forest inventory: (i) forest change detection, and (ii) the nearest neighbor technique.

The process of analyzing image data from two or more periods for the purpose of mapping cover change is commonly referred to as change detection (McRoberts et al. 2010). The principles of satellite image-based forest change detection were first discussed in detail more than a decade ago (Häme 1991, Olsson 1994, Varjo 1997) and are still a subject of current research and interest (Kennedy et al. 2009, McRoberts et al. 2010). Forests can be considered to grow at a constant rate of change, divided into long-term, short-term and rapid change (Häme 1991). Long-term change is usually connected to the growth of the stand, and even that can be monitored using state-of-the-art remote sensing techniques such as aerial imaging and laser scanning (Hyyppa et al. 2008). Satellite remote sensing can be considered to be a practical technique for long-term change observations, in particular because data with image characteristics suitable for monitoring forest changes are available for most of the Earth's surface for the past 40 years (e.g., the Landsat program - Wulder et al. 2008, McRoberts et al. 2010). Short-term or seasonal changes, usually related to reforestation, defoliation etc. can be monitored by satellite image-based remote sensing (Vogelmann et al. 2009, McRoberts \& Walters 2012). The main challenge for foresters, however, is the detection and measuring of rapid changes such as tree felling, wind damage and so on. Satellite image-based remote sensing has become an essential data source for assessing rapid or abrupt changes, being low cost, easily and readily accessible, yet it still provides adequate information (Kennedy et al. 2009, Townsend et al. 2009). A great variety of change detection approaches have been tested (Singh 1989, Coppin et al. 2004, Kennedy et al. 2009, McRoberts et al. 2010), some of which have focused directly on the assessment of wind damage to forests (Wang \& Xu 2010). In general, methodological approaches for detecting changes in vegetation can be grouped into two primary categories: trajectory analysis and bi-temporal methods (McRoberts \& Walters 2012). Trajectory analyses are based on the use of time series of more than two images to assess the type, extent, progress, trend or temporal pattern of changes over time (Kennedy et al. 2007). Usually, trajectory analyses have been used with data 
from high temporal and coarse spatial resolution sensors (McRoberts et al. 2010). More recently, Landsat time series data have been used to map forest changes (Kennedy et al. 2007, Vogelmann et al. 2009, Gómez et al. 2011). Bi-temporal methods include the analyses of two images acquired at different dates (McRoberts \& Walters 2012). Examples of classical bi-temporal approaches used for change detection are the thresholding of image difference or ratio channels, linear transformations of two temporal data sets, comparisons of two independent image classification results, and direct classification of a multiband data set, etc. (Singh 1989, Häme et al. 1998, Coppin et al. 2004). The detection of rapid changes in forest canopies has been well documented by numerous Scandinavian scientists, but they usually failed to achieve sufficient accuracy when employing satellite image information only, together with conventional algorithms suitable for studies of general land cover change (Häme 1991, Olsson 1994, Varjo 1996). More reliable results were obtained when auxiliary ground information, especially data originating from stand-level inventories, was combined with the satellite images and more sophisticated processing methods based on combinations of several image processing techniques were used (Häme 1991, Varjo 1996, Varjo \& Folving 1997, Häme et al. 1998, Haapanen \& Pekkarinen 2000). Today, the blending of data from different passive sensors or a combination of passive and active sensors is expected to define the future of forest monitoring (McRoberts et al. 2010). The blending of remote sensing data and information available from vector databases could also be a solution. In Lithuania, information available from even relatively outdated stand-wise forest inventory combined with single acquisition date Satellite Pour l'Observation de la Terre version 4 (SPOT-4) HRVIR image resulted in better than $90 \%$ overall final felling detection accuracy (Jonikavičius \& Mozgeris 2011).

Aside from the detection of changes, satellite imagery is considered to be an operational solution for estimating the continuous surfaces of key forest characteristics and providing statistically sound estimates for small areas within the framework of sampling-based, multi-source national forest inventories in some countries (e.g., Tomppo 1993, Nilsson 1997, Tomppo et al. 1999 Gjertsen et al. 2000, Franco-Lopez et al. 2001, Tomppo 2005, Tomppo et al. 2008, McRoberts 2012). This is based on the use of field sample plot data measured within the frames of some sampling-based forest inventories, together with low-cost, readily accessible satellite imagery, mainly the Landsat Thematic Mapper (TM) and $k$-nearest neighbor $(k-\mathrm{NN})$ prediction. The basic concept is that "field measurements in a cer-

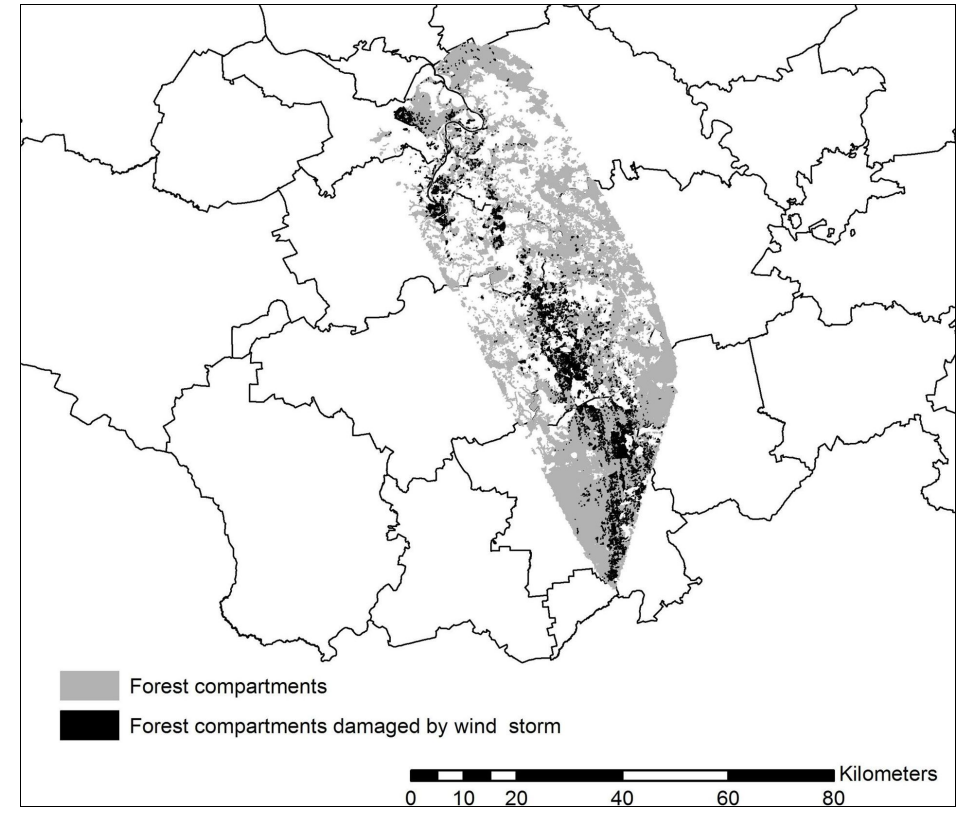

Fig. 1 - The study area.

tain area can also be made use of in neighboring areas by employing a relevant extrapolating, or «information borrowing» technique" (Tomppo 2005).

For those units that lack field observations, sampling of the units that are spatially nearest to, or that most closely resemble the characteristics of (i.e., neighbors), are used as information for predictions on subsequent units (McRoberts 2012). The nearest neighbor technique has been successfully employed to produce forest maps (Franco-Lopez et al. 2001, Reese et al. 2003, McRoberts et al. 2010) and forest resource estimates at the municipality level (Tomppo et al. 2008), but the method has encountered some difficulties at the forest compartment, or division, level (McRoberts 2008). It has also been successfully applied in Lithuania for recording an inventory of mature forests to obtain statistically reliable total volume estimates for forestry districts (areas of about 500 ha Jonikavičius \& Mozgeris 2009), but has failed at the forest compartment level (Jonikavičius \& Mozgeris 2010).

A wind storm occurred on 8 August 2010 damaged about $12 \%$ of all Lithuanian forests. Wind speed exceeded $26 \mathrm{~m} / \mathrm{s}$. In total, 140 thousands ha of damaged forest stands consisting of 3.82 million $\mathrm{m}^{3}$ of damaged stem volume were inventoried by the State Forest Service. Of all stands, $76 \%$ were slightly damaged (less than $5 \%$ stem volume damaged), and $15 \%$ were moderately damaged (6-30\%). Stands on 13000 ha had already been felled (2011) or were to be removed in the very near future (Forest Resources of Lithuania, NFI 2011, Ministry of Environment, State Forest Service http://www.amvmt.lt). Preliminary field assessments of the damage immediately after the storm produced no more than a rough es- timate of the amount and spatial location of damaged stands. An aerial photography survey was also carried out towards the end of 2010 , but this rather costly project required the efforts of highly qualified personnel. Finally, a field survey based on sampling methods carried out in 2011 produced reliable statistics on damaged and harvested timber, but this information became available far too late for operational planning purposes. Thus, the key question to be answered is: would satellite imagery provide opportunities for the timely assessment of wind storm damage and also meet the requirements of Lithuanian forestry authorities for estimating damage location and damaged stem volume?

\section{Material and methods}

Areas potentially affected by the wind storm were photographed in late September 2010 to meet the requirements of forest inventory orthophotographic mapping (Mozgeris et al. 2008). Color infrared orthophotos with a resolution of $0.5 \mathrm{~m} \mathrm{x} 0.5 \mathrm{~m}$ were manually interpreted onscreen to identify the levels of damage inside each forest compartment along the wind storm track. Forest compartments were split into smaller polygons if the continuous wind-damaged area exceeded 0.5 ha. Then, the resulting polygons were assigned damage classification classes 0 to 4 , where: $0=$ no damage; $1=$ less than $25 \%$ of the stand volume damaged; $2=25-50 \%$ damaged; $3=50-75 \%$ damaged; and $4=$ more than $75 \%$ damaged. There were 12181 polygons identified in damage class 1 or more with an average area of 0.9 ha. The actual percentage value of the damage was also identified for each polygon. A minimum boundary rectangle was generated around all forest compartments with $>0 \%$ 
damage, using standard ArcGIS software functionality. All forest compartments enclosed by the rectangle were selected from the geographical database of the Lithuanian State Forest cadaster for subsequent study. The total number of compartments in the minimum bounding rectangle was 71979 , with an average area of 1.7 ha.

Two cloud-free Landsat 5 TM images (WRS path/row 187/022) were acquired from the USGS EarthExplorer (http://earth explorer.usgs.gov) for the dates June 5, 2010 (hereafter referred to as the earlier image) and September 25, 2010 (the later image) The satellite images were processed to the geocoded products using ground control points measured on topographic maps and in the field, stored in Lithuanian coordinate system LKS94. Relative radiometric calibration was applied to the later image using the multiple linear regression technique of Olsson (1994 - eqn. 1):

$$
\begin{aligned}
\hat{Y}_{b}= & a_{0}+a_{1} X_{T M 1}+a_{2} X_{T M 2}+ \\
& a_{3} X_{T M 3}+a_{4} X_{T M 4}+a_{5} X_{T M 5}+ \\
& a_{6} X_{T M 7}
\end{aligned}
$$

where $\hat{Y}_{\mathrm{b}}$ is the calibrated pixel value for each band (b) of the later image, $a_{0}, a_{1}, \ldots a_{6}$ are regression coefficients; and $X_{\mathrm{TM} 1}, \ldots X_{\mathrm{TM} 5}$, $X_{\mathrm{TM} 7}$ are the original pixel values of the later image.

Only the pixels located within the forest in the study area were used to develop the regression models for relative image calibration. The final spatial extent of the study area was defined by the intersection of satellite images available for the study and the minimum bounding rectangle around the forest compartments damaged by the wind storm on 8 August 2010 (Fig. 1).

Next, six image difference grids corresponding to the TM bands were created by subtracting the calibrated pixel values of the later image from corresponding pixel values of the earlier image. Aggregate image difference values were obtained as follows (Eastman \& McKendry 1991 - eqn. 2):

$$
X_{T M}=\sqrt{X_{T M 1}^{2}+X_{T M 2}^{2}+X_{T M 3}^{2}+X_{T M 4}^{2}+X_{T M S}^{2}+X_{T M 7}^{2}}
$$

where $X_{\mathrm{TM} 1}, \ldots, X_{\mathrm{TM} 5}, X_{\mathrm{TM} 7}$ are image difference values of corresponding TM bands.

Simple thresholding of the aggregated difference image was applied to create binary "change/no change" masks, stored as raster grids with the same properties as the satellite images. The value of $X_{\mathrm{TM}}$ was iteratively changed from 1 to 20 using step $=1$, and 20 versions of "change/no change" grids were generated. Initially it was thought that, in addition to the $X_{\mathrm{TM}}$ value, the interpreted change in the validation data set might have some influence on the interpretation of the results. Thus, based on the vector data of the mapped wind damage extents, a series of ras- ter grids was constructed to represent actual change due to wind damage. Polygons (forest compartments or parts of forest compartments) with percentages of stand volume damaged greater than 50,60, 70, 80, 90 and 100 , respectively, were converted to raster grids using the same grid properties as for the aggregated difference image. Error matrices (Lillesand et al. 2008) were then created to assess the classification accuracy for all combinations of $X_{\mathrm{TM}}$ and the percentage of stand volume that had been damaged.

Having determined the threshold value of $X_{\mathrm{TM}}$ that resulted in the highest overall accuracy of change classification (actually, 13), the percentage of area changed in each forest compartment was calculated based on the corresponding "change/no change" grid.

In addition to the spatial location of winddamaged forest areas, the volume of damaged forest stands is considered to be equally important in Lithuanian forestry. Information on the total stand volume in the forest compartments is usually available from the stand register of the State Forest cadaster. For each compartment, two methods of resolving the wind-damaged stand volume were used:

- the stand volume accessed from the stand register was multiplied by the percentage of area changed, as determined for each individual compartment using the "change/ no change" grid (hereafter referred to as Solution 1);

- a special approach was developed to integrate the solutions originating from satellite image-based change detection and nearest neighbor techniques, based on $k$-nearest neighbor $(k-\mathrm{NN})$ prediction and using auxiliary information from the "change/no change" grid and the stand register of the State Forest cadaster (Solution 2).

The $k$-NN method is a multi-dimensional version of the inverse distance-weighted technique, briefly described as follows (Tomppo 1993): the Euclidean distance $d_{\mathrm{i}, \mathrm{p}}$ is calculated between each first-phase observation unit $p$ (in this case, $p$ is a forest compartment inside the test area) in $n$-dimensional feature space of auxiliary information, and a second-phase observation unit $i$ with a known value of wind-damaged stand volume (here we used 9278 randomly selected compartments from the wind damage assessment data set obtained from orthophotomap interpretation representing all tree species, age class, relative stocking level and wind damage class combinations in the test area). Here, $n$ refers to the total number of layers of auxiliary information-age class, volume per hectare, relative stocking index, area of the compartment originating from the stand-wise forest inventory, and the percentage of area that has been classified as changed, according to satellite images; and $k$ represents the distances $d_{\mathrm{i}, \mathrm{p}}-d_{(1), \mathrm{p}} \ldots d_{(\mathrm{k}) \mathrm{p}},\left(d_{(1), \mathrm{p}} \leq \ldots \leq d_{(\mathrm{k}) \mathrm{p}}\right)$ found and the weight is calculated from (eqn. 3):

$$
w_{(i), p}=\frac{1}{d_{(i), p}^{t}} / \sum_{i=1}^{k} \frac{1}{d_{(i), p}^{t}}
$$

The value of wind-damaged volume per hectare for each compartment $p$ of firstphase observation is given by (eqn. 4 ):

$$
\hat{m}_{p}=\sum_{j=1}^{k} w_{(j), p} \cdot m_{(j), p}
$$

where $m_{(\mathrm{j}) \mathrm{p},}, j=1, \ldots k$ are the values of the wind-damaged volume per hectare of $k$ second-phase observation units nearest to $p$ in $n$-dimensional feature space.

The list of layers of auxiliary information and the values of $k$ and $t$ were iteratively chosen using leave-one-out technique in order to minimize the prediction root mean square error. The lowest prediction root mean square errors were achieved with all layers of auxiliary information and a value of $t$ equal to 1 . Values of $k$ ranging from 1 to 30 were tested and the value $k=10$ was chosen for further investigation because it was the smallest value of $k$ for which the root mean square was not more than $1 \%$ greater than the overall smallest value (following the recommendations by McRoberts 2012).

To obtain the wind-damaged volumes in all compartments of the test area to be used for validation, we simply multiplied the stand volume (as accessed from the stand register) by the damage percentage interpreted from the orthophotomaps.

Conventional GIS and remote sensing packages (ArcGIS, PCI Geomatica) were used to perform the GIS processing tasks, working with satellite and aerial images. The Most Similar Neighbor (MSN) program (Moeur \& Stage 1995, Crookston et al. 2002) was used to calculate the Euclidean distances used in the $k$-NN predictions.

\section{Results and discussion}

Increasing the threshold value to consider the value of a difference image caused an increase in the overall identification accuracy of wind-damaged areas (Fig. 2) up to a value of $X_{\mathrm{TM}}=13$, then effectively stabilized at 95 $98 \%$. The same trends were observed (not shown in Fig. 2) regarding the correlation of $X_{\text {TM }}$ with the $\kappa$ statistic (Lillesand et al. 2008). The absolute values of $\kappa$, which is a measure of how much the classification being validated exceeds a chance classification, were moderate (about 0.5-0.6), indicating that the relationship is independent of tree species, and also of the interpretation of "change" - that is, the percentage of the volume actually damaged being considered as a "change".

The percentage of volume damaged by the wind storm was estimated for almost 64000 forest compartments in the study area using the selected "change/no change" grid. How- 
Fig. 2 - Overall accuracy of classification of wind-damaged areas, with respect to the percentage of volume actually damaged being considered as a change, and the threshold value of difference image identifying a change: (A) pine stands; (B) spruce stands; (C) deciduous stands.
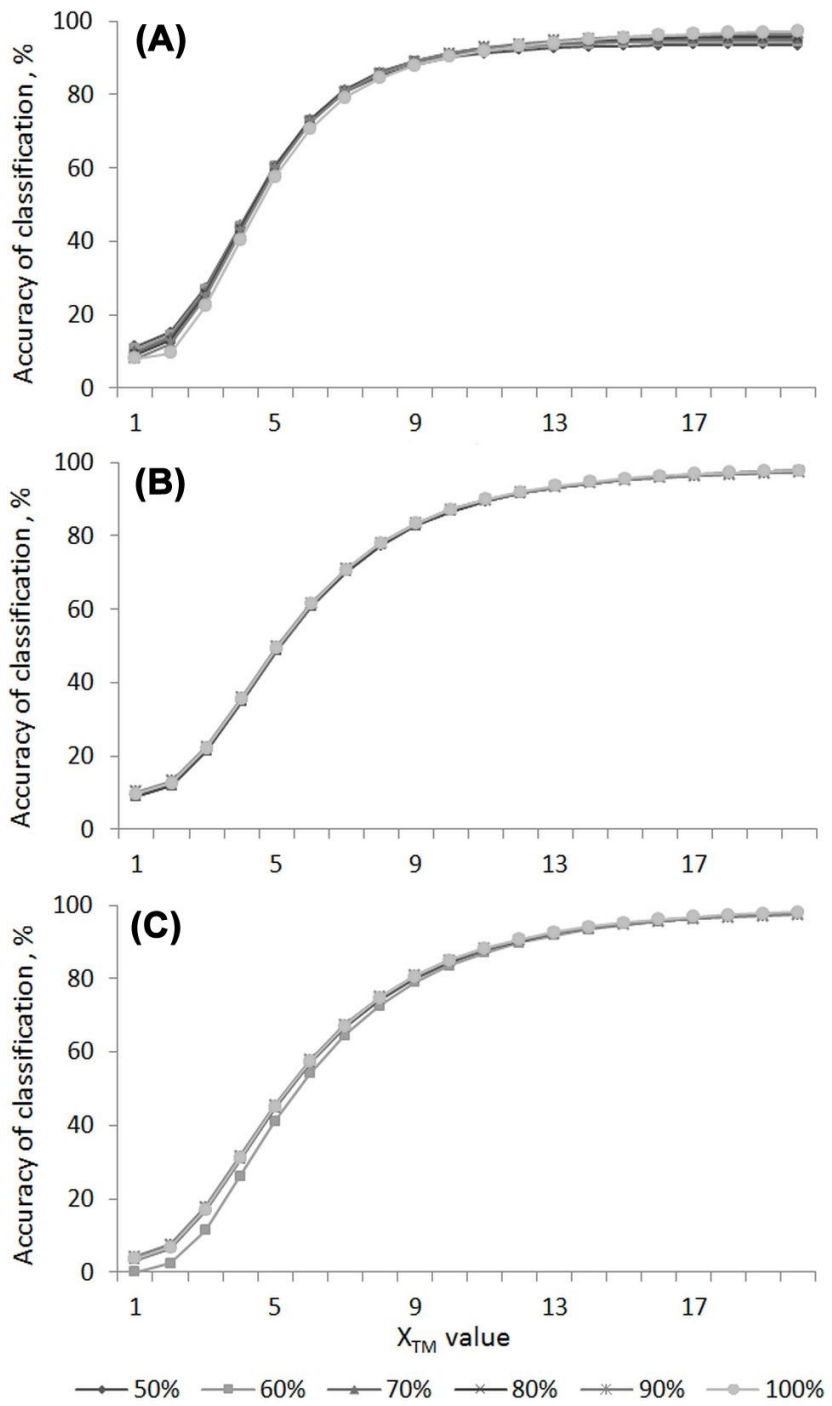

ever, only $17.3 \%$ of the forest compartments were actually damaged $(20.1 \%$ in pine stands, $13.9 \%$ for spruce and $12.9 \%$ for deciduous trees). The Kolmogorov-Smirnov test was used to check the null hypothesis that the distribution of damaged volumes per unit area in the compartment was normal, but the $p$-value was lower than the significance level $\alpha=0.05(p<0.0001)$ in all cases, thus rejecting the null hypothesis.

An inspection of the classified image difference grid revealed that approximately $17 \%$ of all forest compartments contained at least one "change" cell; however, the area of a compartment identified as "changed" was practically always less than the actual damage percentage. Therefore, the total volume of damaged forest in the study area estimated using the Solution 1 (i.e., using only the difference between two satellite images) was much less than the estimates obtained from the labor- and time-consuming interpretation of aerial imagery based orthophotos (Tab. 1). The total volume was underestimated by $41.8 \%$; for predominantly pine compartments, underestimation was even greater at
$44.9 \%$. This might be explained as being a result of the dispersed nature of the distribution of wind-damaged trees throughout the whole area of the compartment, especially when the damage classes were low, such as 1 or 2. Thus, the value $X_{\text {TM }}$ was too low at some locations to identify a "change". The difference between actual damage percentage and the percentage of "changed" area for the compartment was found to be correlated weakly, yet still at a significant level statistically, with the characteristics of the forest stand in the compartment (those used later as auxiliary data in the $k$-NN prediction). The largest Pearson's correlation coefficients were observed for stand volume $(0.14$ for pine, 0.16 for spruce and 0.13 for deciduous stands), area of the compartment (respectively $-0.14,-0.13$ and -0.08 ), and age class $(0.08,0.10$ and 0.09$)$.

To summarize, the forest damage estimates arrived at by using Solution 1 lay outside the acceptable range for Lithuanian forestry. However, the introduction of auxiliary information other than satellite imagery, which is readily available from the State Forest cadastre (Solution 2), improved the total estimates of wind-damaged forest volume notably (Tab. 1). The total volume of damaged trees was underestimated by just $2.5 \%$, while the underestimation for the most significant economically and more abundant pine-dominated stands was even less, at $2.1 \%$. We may consider the achieved underestimations to be well within acceptable limits, since a general requirement of the Lithuanian forest inventory is to aim to have the total estimated volume of an inventory object larger than 1000 ha to be true within $\pm 5 \%$.

The use of the $k$-NN method in forest inventories is usually connected to samplingbased inventories and for generating statistics, basically volume, for areas larger than a forest compartment. As mentioned above, attempts to analyze data at the forest compartment level have not always been successful, and studies of this topic are only modestly represented in the literature. In USA, forest inventory sample plot data, Landsat $\mathrm{TM}$ satellite imagery, and the $k$-NN technique have been used to produce stand-level estimates (McRoberts 2008). He found that estimates of stand-level stem density and basal area means were within confidence in-

Tab. 1 - Total volumes of wind-damaged trees in the study area. (Solution 1): prediction using only difference of two satellite images; (Solu tion 2): prediction using $k$-NN and information from satellite images and stand-wise forest inventory; (Validation): aerial photography-based inventory. For more details, see text.

\begin{tabular}{lcccccc}
\hline \multirow{2}{*}{$\begin{array}{l}\text { Prevailing } \\
\text { species }\end{array}$} & $\begin{array}{c}\text { No of } \\
\text { compartments }\end{array}$ & \multicolumn{3}{c}{$\begin{array}{c}\text { Total volume of wind } \\
\text { damaged trees (1000 } \mathbf{~ m}^{\mathbf{3}} \text { ) }\end{array}$} & \multicolumn{2}{c}{$\begin{array}{c}\text { Difference compared to aerial } \\
\text { photography-based inventory data (\%) }\end{array}$} \\
\cline { 3 - 7 } & & Solution $\mathbf{1}$ & Solution 2 & Validation & Solution 1 & Solution 2 \\
\hline Pine & 37632 & 649 & 1153.4 & 1178.8 & -44.9 & -2.1 \\
Spruce & 8633 & 152.3 & 227.4 & 233.5 & -34.7 & -2.6 \\
Deciduous & 17495 & 133.6 & 186.3 & 194.5 & -31.3 & -4.2 \\
All & 63760 & 934.9 & 1567.1 & 1606.8 & -41.8 & -2.5 \\
\hline
\end{tabular}


tervals for validation estimates for around $90 \%$ of stands. Other research projects used potentially more accurate - therefore more costly - remote sensing data, or else considered somewhat elementary forest conditions. Previously, the approach to obtain forest compartment-level estimates has mainly involved the use of aerial imagery and historical forest inventory records (Moeur \& Stage 1995, Temesgen et al. 2003), aerial images together with, or independently of, data derived from laser scanning (Næsset 1997, 2004, 2007, Means et al. 1999, Holmström et al. 2001, Muinonen et al. 2001, Holmgren 2004, Eskelson et al. 2008). More recently, similar research in Lithuania reached the conclusion that summary statistics only, such as the mean volume of growing stock per hectare for some areas, could be applicable operationally if the $k$-NN predictions were done at a forest compartment level (Jonikavičius \& Mozgeris 2010). However, it seems that the estimation of the stand volume lost due to natural disasters using a similar approach has not previously been studied.

Similarly to most of the research mentioned above, the prediction unit in the present study was a forest compartment. The prediction accuracies expressed in terms of root mean square error are usually quite poor at the prediction unit level using non-parametric methods (Mozgeris 2008) and the bias is low. The root mean square error tends to drop further for larger aggregations. We did not report in details the prediction accuracies at a forest compartment level (they were used to choose the settings for $k$-NN prediction), bearing in mind that most of the compartments did not exhibit any damage neither in the field nor in predictions. Aggregated damage estimation for the whole study area is compatible with the major objective of such assessment, which is to provide general statistics for strategic planning related to the elimination of the consequences of a natural calamity.

One of the major features of non-parametric methods is that we may expect no unrealistic predictions to occur if the reference material is appropriate. In fact, although all forest compartments in the study area were inventoried using color infrared orthophotos and provided with the forest damage characteristics, under operational conditions it may be quite difficult to construct such a set of second-phase observations. The extents of natural calamities such as wind storm damage are first roughly audited in Lithuania by field visits by state forest officers, as has been done in this particular case. Data is usually collected for some parts of compartments that are accessible, known, concentrated on state-owned land, etc. Assuming that the total damage estimates may differ under other conditions, for rapid assessment of forest damage caused by wind storms we still consider the approach using satellite images and stand-wise forest inventory data described in this paper as possessing some potential. The main reason for such optimism is the fact that both satellite images and forest inventory data are available free of charge.

\section{Conclusion}

Rapid changes in a forest may be assessed using a combination of satellite images and stand-wise forest inventory data. The overall accuracy of identification of wind-damaged areas achieved, based solely on difference images available from two-date satellite imagery, was $95-98 \%$. The proposed solution for predicting the percentage of damage in terms of wind-fallen or broken stem volume for each forest compartment inside the zone potentially affected by the wind storm using the non-parametric $k$-nearest neighbors technique and classified difference images originating from two satellite images captured on dates before and after the wind storm event, together with forest compartment characteristics accessed from the Lithuanian State Forest cadastre, resulted in acceptable accuracies at a study area level. Total winddamaged volume in predominantly pine compartments $\left(\sim 1180000 \mathrm{~m}^{3}\right)$ was underestimated by $2.2 \%$, in predominantly spruce compartments $\left(\sim 233000 \mathrm{~m}^{3}\right)$ by $2.6 \%$, and in predominantly deciduous compartments $\left(\sim 195000 \mathrm{~m}^{3}\right)$ by $4.2 \%$. The overall underestimation was $2.5 \%$.

\section{References}

Coppin P, Jonckheere I, Nackaerts K, Muys B, Lambin E (2004). Digital change detection methods in ecosystem monitoring: a review. International Journal of Remote Sensing 25: 15651596. - doi: 10.1080/0143116031000101675 Crookston NL, Moeur M, Renner D (2002). Users guide to the most similar neighbor imputation program version 2. Gen. Tech. Rep. RMRS-GTR-96, Rocky Mountain Research Station, USDA Forest Service, Ogden, UT, USA, pp. 35. Eastman JR, McKendry JE (1991). Explorations in geographic information systems technology. Volume 1. Change and time series analysis. United Nations Institute for Training and Research, United Nations Environment Program Global Resource Information Database, pp. 86.

Eskelson BNI, Temesgen H, Barrett TM (2008). Comparison of stratified and non-stratified most similar neighbour imputation for estimating stand tables. Forestry 81 (2): 125-134. - doi: 10.1093/forestry/cpn003

Franco-Lopez H, Ek AR, Bauer ME (2001). Estimation and mapping of forest stand density, volume, and cover type using the $k$-nearest neighbors method. Remote Sensing of Environment 77: 251- 274. - doi: 10.1016/S0034-4257 (01)00209-7

Gjertsen AK, Tomter S, Tomppo E (2000). Com- bined use of NFI sample plots and Landsat TM data to provide forest information on municipality level. In: Proceedings of IUFRO conference "Remote sensing and forest monitoring" (Zawila-Niedzwinski T, Brach $\mathrm{M}$ eds). Rogow (Poland) 1-3 Jun. 1999. Office for Official Publications of the European Communities, Luxembourg, pp. 167-174.

Gómez C, White JC, Wulder MA (2011). Characterizing the state and processes of change in a dynamic forest environment using hierarchical spatio-temporal segmentation. Remote Sensing of Environment 115: 1665-1679. - doi: 10.1016/ j.rse.2011.02.025

Haapanen R, Pekkarinen A (2000). Utilising satellite imagery and digital detection of clear cuttings for timber supply management. International Archives of Photogrammetry and Remote Sensing, vol. XXXIII, Part B7, pp. 481-488.

Häme T (1991). Spectral interpretation of changes in forest using satellite scanner images. Acta Forestalia Fennica 222: 112.

Häme T, Heiler I, San Miguel-Ayanz J (1998). An unsupervised change detection and recognition system for forestry. International Journal of Remote Sensing 19 (6): 1079-1099. - doi: 10.1080/ 014311698215612

Holmgren J (2004). Prediction of tree height, basal area and stem volume in forest stands using airborne laser scanning. Scandinavian Journal of Forest Research 19: 543-553. - doi: 10.1080/ 02827580410019472

Holmström H, Nilsson M, Stahl G (2001). Simultaneous estimations of forest parameters using aerial photograph interpreted data and the $k$ nearest neighbour method. Scandinavian Journal of Forest Research 16: 67-78. - doi: 10.1080 028275801300004424

Hyyppa J, Hyyppa H, Leckie D, Gougeon F, Yu X, Maltamo M (2008). Review of methods of small-footprint airborne laser scanning for extracting forest inventory data in boreal forests. International Journal of Remote Sensing 29 (5): 1339-1366 - doi: 10.1080/01431160701736489 Jonikavičius D, Mozgeris G (2009). Estimation of volumes for mature forests using the k-nearest neighbor technique and satellite image. In: Proccedings of the $4^{\text {th }}$ International Conference "Rural development 2009". Akademija (Lithuania) 15-17 October 2009, vol. 4 (2), pp. 235-240. Jonikavičius D, Mozgeris G (2010). Estimation of forest parameters using the non-parametric techniques and satellite images at compartment level. In: Proceedings of the annual $16^{\text {th }}$ International Conference "Research for rural development 2010". Jelgava (Latvia) 19-21 May 2010, pp. 194-200.

Jonikavičius D, Mozgeris G (2011). Forest change detection using medium resolution single acquisition time satellite images. In: Proceedings of the "Biennial International Symposium Forest and Sustainable Development". University of Brasov, Faculty of Silviculture and Forest Engineering, Brasov (Rumania) 15-16 October 2010. Transilvania University Press, pp. 421-426.

Kennedy RE, Cohen WB, Schroeder TA (2007). 
Trajectory-based change detection for automated characterization of forest disturbance dynamics. Remote Sensing of Environment 110: 370-386. doi: 10.1016/j.rse.2007.03.010

Kennedy RE, Townsend PA, Gross JE, Cohen WB, Bolstad P, Wang YQ, Adams P (2009). Remote sensing change detection tools for natural resource managers: Understanding concepts and trade offs in the design of landscape monitoring projects. Remote Sensing of Environment 113: 1382-1396. - doi: 10.1016/j.rse.2008.07.018

Lillesand TM, Kiefer RW, Chipman JW (2008). Remote sensing and image interpretation $\left(6^{\text {th }}\right.$ edn). John Wiley and Sons Inc., USA, pp. 756.

McRoberts RE (2008). Using satellite imagery and the $k$-nearest neighbors technique as a bridge between strategic and management forest inventories. Remote Sensing of Environment 112: 212-222 - doi: 10.1016/j.rse.2007.07.025

McRoberts RE, Cohen WB, Næsset E, Stehman SV, Tomppo E (2010). Using remotely sensed data to construct and assess forest attribute maps and related spatial products, Scandinavian Journal of Forest Research 25 (4): 340-367.

McRoberts RE (2012). Estimating forest attribute parameters for small areas using nearest neighbors techniques. Forest Ecology and Management 272: 3-12. - doi: 10.1016/j.foreco.2011. 06.039

McRoberts RE, Walters BF (2012). Statistical inference for remote sensing-based estimates of net deforestation. Remote Sensing of Environment 124: 394-401. - doi: 10.1016/j.rse.2012.05.011

Means JE, Acker SA, Harding DJ, Blair JB, Lefsky MA, Cohen WB, Harmon ME, McKee WA (1999). Use of large-footprint scanning airborne lidar to estimate forest stand characteristics in the Western Cascades of Oregon. Remote Sensing of Environment 67: 298-308. - doi: 10.1016/S0034-4257(98)00091-1

Moeur M, Stage AR (1995). Most similar neighbor: an improved sampling inference procedure for natural resource planning. Forest Science 41: 337-359.

Mozgeris G (2008). Estimation and use of continuous surfeces of forest parameters: options for Lithuanian forest inventory. Baltic Forestry 14 (2): 176-184.

Mozgeris G, Galaune A, Palicinas M (2008). Systemy informacji geograficznej w urzdzaniu lasu na Litwie - dekada praktycznego stosowania. Sylwan 1: 58-63.

Muinonen E, Maltamo M, Hyppanen H, Vaini- kainen V (2001). Forest stand characteristics estimation using a most similar neighbor approach and image spatial structure information. Remote Sensing of Environment 78: 223-228. - doi: 10.1016/S0034-4257(01)00220-6

Næsset E (1997). Estimating timber volume of forest stands using airborne laser scanner data. Remote Sensing of Environment 61: 246-253. doi: 10.1016/S0034-4257(97)00041-2

Næsset E (2004). Effects of different flying altitudes on biophysical stand properties estimated from canopy height and density measured with a small-footprint airborne scanning laser. Remote Sensing of Environment 91: 243- 255. - doi: 10.1016/j.rse.2004.03.009

Næsset E (2007). Airborne laser scanning as a method in operational forest inventory: status of accuracy assessments accomplished in Scandinavia. Scandinavian Journal of Forest Research 22: 433-442. - doi: 10.1080/02827580701672 147

Nilsson M (1997). Estimation of forest variables using satellite image data and airborne LiDAR. $\mathrm{PhD}$ thesis, Department of Forest Resource Management and Geomatics, Swedish University of Agricultural Sciences, Umea, Sweden. Acta Universitatis Agriculturae Sueciae, Silvestrias, pp. 17.

Olsson H (1994). Monitoring of local reflectance changes in boreal forests using satellite data, Dissertation, Biometry and Forest Management Department, Swedish University of Agricultural Sciences, Umea, Sweden.

Reese H, Nilsson M, Granqvist Pahlén T, Hagner O, Joyce S, Tingelöf U, Egberth M, Olsson H (2003). Countrywide estimates of forest variables using satellite data and field data from the National Forest Inventory. Ambio 32 (8): 542548.

Singh A (1989). Digital change detection techniques using remotely-sensed data. International Journal of Remote Sensing 10 (6): 989-1003. doi: 10.1080/01431168908903939

Temesgen H, LeMay VM, Froese KL, Marshall PL (2003). Imputing tree-lists from aerial attributes for complex stands of south-eastern British Columbia. Forest Ecology and Management 177: 277-285. - doi: 10.1016/S0378-1127(02)003213

Tomppo E (1993). Multi-source national forest inventory of Finland. In: Proceedings of the IUFRO S4.02 "Ilvessalo Symposium on National Forest Inventories". Finnish Forest Research In- stitute, University of Helsinki, Helsinki, Finland, pp. 52-60.

Tomppo E, Goulding C, Katila M (1999). Adapting Finnish multisource forest inventory techniques to the New Zealand preharvest inventory. Scandinavian Journal of Forest Research 14: 182-192. - doi: 10.1080/02827589950152917

Tomppo E (2005). The Finnish multisource national forest inventory - small area estimation and map production. In: "Forest inventory: methodology and applications" (Kangas A, Maltamo M eds). Springer, Berlin, Germany, pp. 191-220. Tomppo E, Olsson H, Ståhl G, Nilsson M, Hagner O, Katila M (2008). Combining national forest inventory field plots and remote sensing data for forest databases. Remote Sensing of Environment 112: 1982-1999. - doi: 10.1016/j.rse.2007. 03.032

Townsend PA, Lookingbill TR, Kingdon CC, Gardner RH (2009). Spatial pattern analysis for monitoring protected areas. Remote Sensing of Environment 113:1410-1420. - doi: 10.1016/j. rse.2008.05.023

Varjo J (1996). A nonparametric method for controlling stand register by satellite data. The International Journal of Remote Sensing 17: 43-67. doi: 10.1080/01431169608948986

Varjo J (1997). Change detection and controlling forest information using multi-temporal Landsat TM imagery. Acta Forestalia Fennica 258: 64.

Varjo J, Folving S (1997). Monitoring of forest changes using unsupervised methods: a case study from boreal forest on mineral soils. Scandinavian Journal of Forest Research 12: $362-$ 369. - doi: 10.1080/02827589709355424

Vogelmann JE, Tolk B, Zhu Zc (2009). Monitoring forest changes in the south western United States using multitemporal Landsat data. Remote Sensing of Environment 113: 1739-1748. - doi: 10.1016/j.rse.2009.04.014

Wang F, Xu YJ (2010). Comparison of remote sensing change detection techniques for assessing hurricane damage to forests. Environmental Monitoring and Assessment 162:311-326. - doi: 10.1007/s10661-009-0798-8

Wulder MA, White JC, Goward SN, Masek JG, Irons JR, Herold M, Cohen WB, Loveland TR, Woodcock CE (2008). Landsat continuity: Issues and opportunities for land cover monitoring. Remote Sensing of Environment 112: 955-969. doi: $10.1016 /$ j.rse.2007.07.004 